\title{
Anal Canal Duplication in a 40-Year-Old Adult
}

\author{
Jessica Neves ${ }^{\mathrm{a}, \mathrm{b}}$, Raquel Dias ${ }^{\mathrm{a}}$, Hugo Ribeiro ${ }^{\mathrm{a}}$, Marta Ferreira ${ }^{\mathrm{a}}$, \\ | Narcisa Guimaraes ${ }^{\mathrm{a}}$, Ines Monica ${ }^{\mathrm{a}}$, Nuno Azenha ${ }^{\mathrm{a}}$, \\ Lucilia Conceicao $^{\text {a }}$
}

\begin{abstract}
Anal canal duplication (ACD) is the rarest congenital malformation of the digestive tract and is associated with other congenital malformations. The clinical case reports a 40 years old woman who had two episodes of anal abscesses treated with surgical drainage within 1 year. In proctology consultation, the examination revealed a structure in the midline, posterior to the native anus. Pelvic magnetic resonance imaging and anal echoendoscopy confirmed the presence of a tubular structure posterior to the anal canal, compatible with duplication of the anal canal. The patient was proposed for surgical excision but refused. Seven years later, the patient had another anal abscess. She was again proposed for surgery and refused. Around 60 cases of ACD are currently described worldwide. The diagnosis is usually made at an early stage of life. Our patient was diagnosed at the age of 40 years, constituting one of the most elderly patient diagnosed with ACD.
\end{abstract}

Keywords: Anal canal duplication; Late diagnosis; Anal abscess

\section{Introduction}

Anal canal duplication (ACD) is the rarest congenital malformation of the digestive tract. It presents in $89 \%$ of cases as an accessory orifice in the perineum, posterior to the true anus [1].

\section{Case Report}

The clinical case reports a 40 years old woman who had two episodes of posterior medial anal abscesses treated with surgical drainage within 1 year. She was referenced for proctology consultation despite being asymptomatic. The examina-

Manuscript submitted August 28, 2017, accepted September 13, 2017

aDepartment of General Surgery, Hospital Distrital da Figueira da Foz, Portugal

${ }^{\text {b} C o r r e s p o n d i n g ~ A u t h o r: ~ J e s s i c a ~ N e v e s, ~ R u a ~ E s p a r g o ~ d e ~ B a i x o, ~ 633, ~} 2^{\circ}$ Recuado, 4520-107 Espargo, Santa Maria da Feira, Portugal.

Email: sicaneves1987@hotmail.com

doi: https://doi.org/10.14740/jmc2902w tion revealed a structure in the midline, posterior to the native anus. It was tubular and cul-de-sac shaped at the digital examination. It was about $3 \mathrm{~cm}$ deep and $1 \mathrm{~cm}$ wide (Fig. 1). The anuscopy of the native anus did not show any abnormalities.

A complementary study was performed using imaging exams. Pelvic magnetic resonance imaging (MRI) (Fig. 2, 3) confirmed the presence of a tubular structure posterior to the anal canal with no fistulous path to the rectal wall or anal canal. The pre-sacred space had no other anomalies. Anal echoendoscopy (Fig. 4) showed a posterior orifice to the anus with sphincteric structures, compatible with duplication of the anal canal. She also performed an abdominal computed tomography (CT) scan and CT colonography that did not show any morphological changes.

Upon confirmation of ACD the patient was proposed for surgical excision but refused. Follow-up was lost.

Seven years later the patient came back to the emergency department due to a new posterior anal abscess. She was again proposed for surgery and refused. Until the present day she maintains surveillance in proctology consultation, asympto-

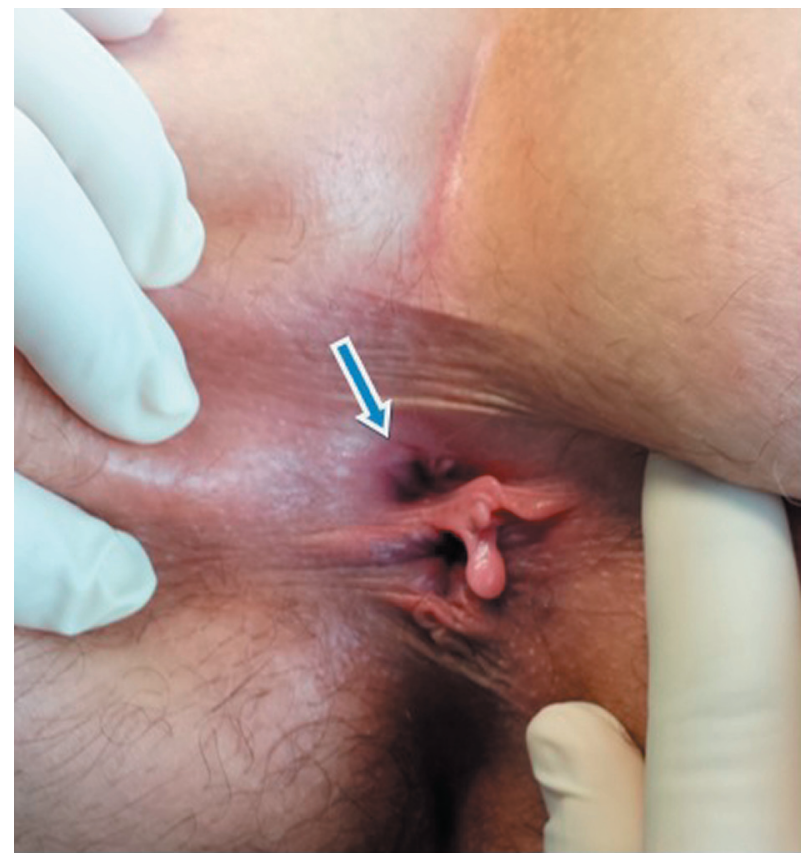

Figure 1. Visual inspection of the anus. The arrow points to the structure in the midline, posterior to the native anus. 


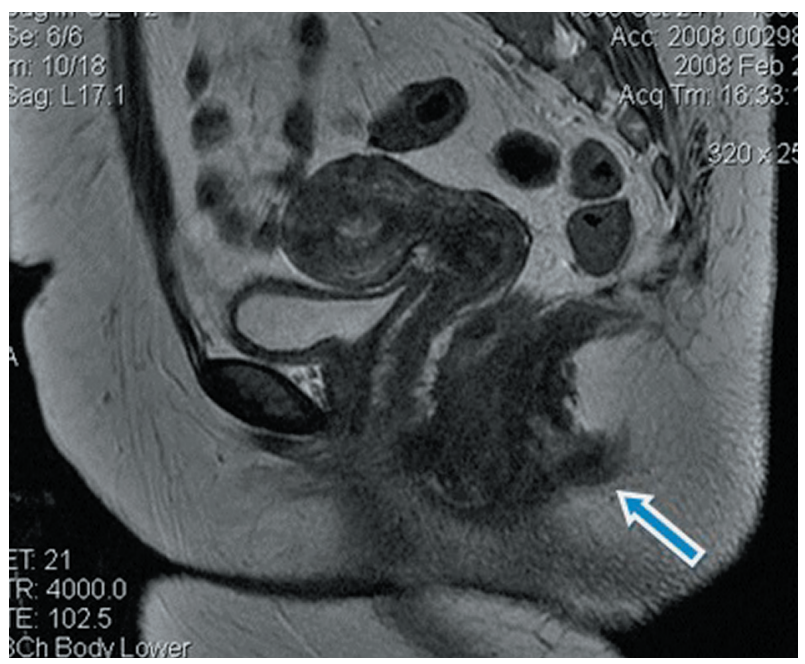

Figure 2. Pelvic MRI showing a tubular structure (arrow) posterior to the anal canal with no fistulous path to the rectal wall or anal canal.

matic.

\section{Discussion}

$\mathrm{ACD}$ is the most uncommon congenital pathology of the di-

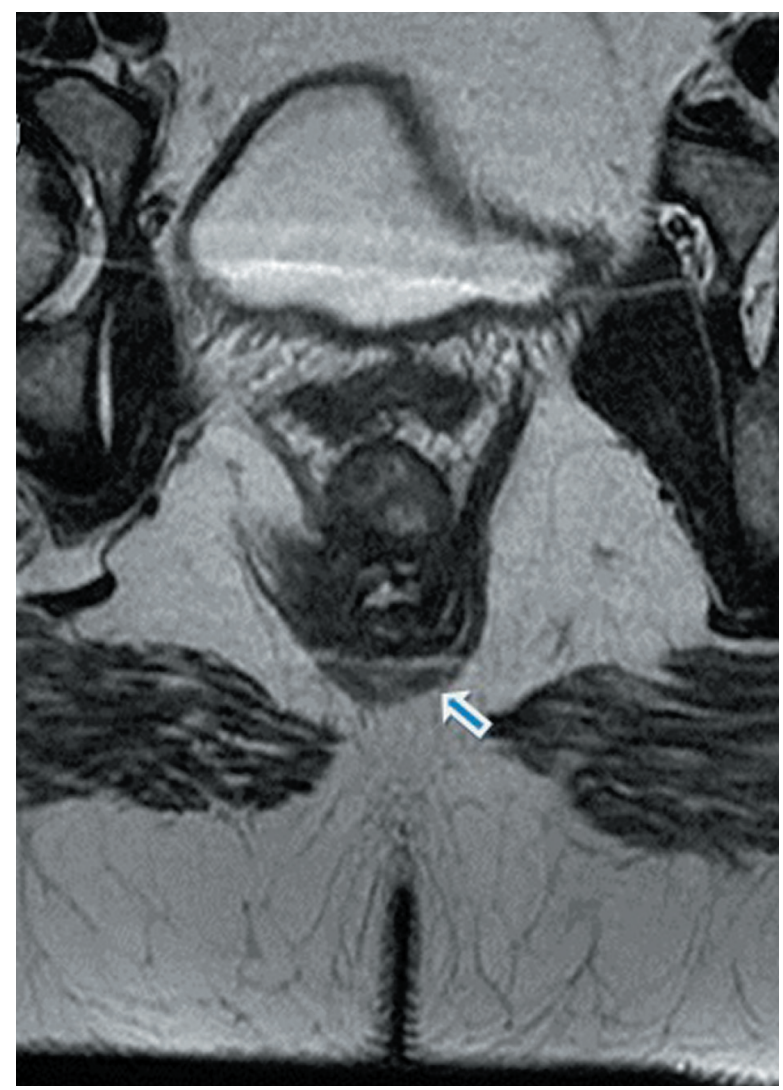

Figure 3. Pelvic MRI showing a tubular structure (arrow) posterior to the anal canal with no fistulous path to the rectal wall or anal canal.

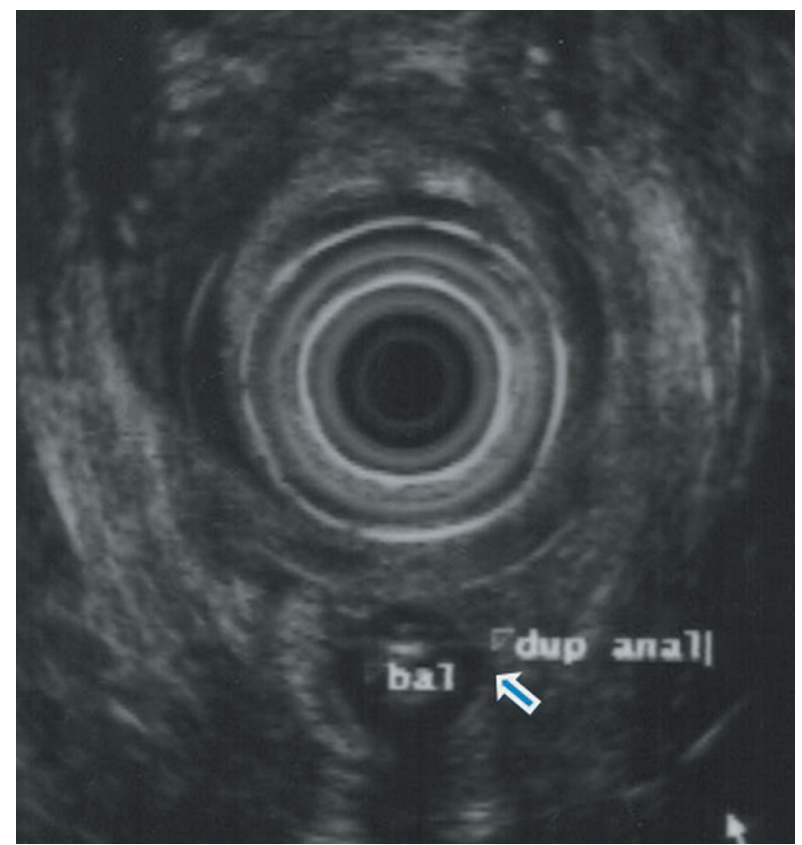

Figure 4. Anal echoendoscopy showed a posterior orifice to the anus with sphincteric structures, compatible with duplication of the anal canal (arrow).

gestive tract and affects mainly women [1-4]. Thirty-five percent of the patients are associated with other congenital malformations, such as dermoid cyst, presacral teratoma, ureteral duplication, lumbosacral meningocele and spina bifida, among others [5].

Diagnosis is usually made in the first year of life by caregivers [1]. In some cases the diagnosis is made at a later stage with the appearance of infectious complications [6]. The majority remains asymptomatic $[1,4]$.

The history and examination of the patient are essential for the diagnosis of ACD. Diagnostic confirmation is made through imaging and/or histological specimen $[1,2]$. Imaging tests also play a role in excluding other pathologies, such as pelvic MRI in the exclusion of presacral congenital malformations and fistulous pathways of the accessory anal canal to the anus or rectum, and abdominopelvic CT in excluding urinary pathology. Barium enemas and fistulography also allow to exclude fistulous paths. Echoendoscopy allows the identification of associated sphincter structures [2].

Surgical excision is the gold standard in order to prevent infectious complications and progression to cancer [3]. The choice of surgical procedure is individual. Stripping the anal mucosa with plication of the muscular wall by perineal route is indicated in ACD without other associated lesions. Its principle is to preserve anatomy and avoid the risk of anal incontinence [1]. Excision by Kraske's pathway is indicated in ACD associated with presacral mass. This approach can also be performed simultaneously with the perineal route. Posterior sagital anorectoplasty is essential in cases where perianal malformations coexists [2].

Infection like anal abscess or progression to neoplasia are the main complications associated with the presence of ACD 
$[1,2,6]$. Neoplasia is the most feared complication, yet it was only described by Dukes and Galvin in 1956. Male individuals and complex anal fistulas were predominant in this subgroup of patients [7]. Due to the likelihood of cancer progression, although apparently overvalued, surveillance with anal inspection and digital examination should be maintained in patients who refuse surgery.

\section{Conclusions}

This case is of particular importance because of its rarity. Around 60 cases of ACD are currently described worldwide. The diagnosis is usually made at an early stage of life. The oldest patient reported was 50 years old. Our patient was diagnosed at the age of 40 years, constituting one of the most elderly patient diagnosed with ACD. There was no need for histological confirmation, since the clinic and imaging assessment were assertive regarding the diagnosis of this congenital malformation.

\section{Conflict of Interest}

No conflict of interest.

\section{References}

1. Carpentier H, Maizlin I, Bliss D. Anal canal duplication: case reviews and summary of the world literature. Pediatr Surg Int. 2009;25(10):911-916.

2. Lisi G, Illiceto MT, Rossi C, Broto JM, Jil-Vernet JM, Lelli Chiesa P. Anal canal duplication: a retrospective analysis of 12 cases from two European pediatric surgical departments. Pediatr Surg Int. 2006;22(12):967-973.

3. Sinnya S, Curtis K, Walsh M, Wong D, Kimble R. Late presentation of anal canal duplication in an adolescent female - a rare diagnosis. Int J Colorectal Dis. 2013;28(8):1175-1176.

4. Van Biervliet S, Maris E, Vande Velde S, Vande Putte D, Meerschaut V, Herregods N, De Bruyne R, et al. Anal canal duplication in an 11-year-old-child. Case Rep Gastrointest Med. 2013;2013:503691.

5. Narci A, Dilek FH, Cetinkursun S. Anal canal duplication. Eur J Pediatr. 2010;169(5):633-635.

6. Mirzaei R, Mahjubi B, Alvandipoor M, Karami MY. Late presentation of anal canal duplication in adults: a series of four rare cases. Ann Coloproctol. 2015;31(1):34-36.

7. Dukes CE, Galvin C. Colloid carcinoma arising within fistulae in the anorectal region. Ann R Coll Surg Engl. $1956 ; 18(4): 246-261$. 